\title{
28 Research Square \\ CD45dimCD34+CD38-CD133+ cells have the potential as leukemic stem cells in acute myeloid leukemia .
}

\section{Sook-Kyoung Heo}

University of Ulsan College of Medicine

\section{Eui-Kyu Noh}

Ulsan University Hospital

\section{Lan Jeong Ju}

University of Ulsan College of Medicine

Jun Young Sung

University of Ulsan College of Medicine

Yoo Kyung Jeong

University of Ulsan College of Medicine

Jaekyung Cheon

Ulsan University Hospital

\section{SuJin Koh}

University of Ulsan College of Medicine

Young Joo Min

University of Ulsan College of Medicine

Yunsuk Choi

University of Ulsan College of Medicine Jae-Cheol Jo ( $\sim$ jcjo97@hanmail.net )

Ulsan University Hospital, University of Ulsan College of Medicine https://orcid.org/0000-0001-60147977

\section{Research article}

Keywords: Acute myeloid leukemia; leukemic stem cells; CD45dimCD34+CD38-CD133+ cells; prognosis; immunophenotyping.

Posted Date: February 25th, 2020

DOI: https://doi.org/10.21203/rs.2.15973/v3 
License: (c) (i) This work is licensed under a Creative Commons Attribution 4.0 International License. Read Full License

Version of Record: A version of this preprint was published at BMC Cancer on April 6th, 2020. See the published version at https://doi.org/10.1186/s12885-020-06760-1. 


\section{Abstract}

Background: Leukemia stem cells (LSCs) in play an important role in the initiation, relapse, and progression of acute myeloid leukemia (AML), and in the development of chemotherapeutic drug resistance in AML. Studies regarding the detection of LSCs and the development of novel therapies for targeting them are extensive. The identification of LSCs and targeting therapies for them has been continuously under investigation. Methods: We examined the levels of CD45 dim CD34 + CD38 - CD133 + cells in bone marrow samples from patients with hematological malignancies and healthy controls, using four-color flow cytometry. Results: Interestingly, the CD45 dim CD34 + CD38 - CD133 + cells were highly expressed in the bone marrow of patients with AML compared to that in healthy controls $(\mathrm{HC})$. Moreover, the proportions of CD45 dim CD34 + CD38 - CD133 + cells were also examined in diverse hematological malignancies, including AML, CML, DLBCL, MM, MDS, HL, ALL, and CLL. LSCs were prominently detected in the BMCs isolated from patients with $A M L$ and $C M L$, but rarely in BMCs isolated from patients with DLBCL, MM, MDS, ALL, CLL, and HL. Additionally, the high CD45 dim CD34 + CD38 - CD133 + cell counts in AML patients served as a significantly poor risk factor for overall and event free survival. Conclusions: Therefore, our results suggest that CD 45 dim CD34 + CD38 - CD133 + cells in AML might potentially serve as LSCs. In addition, this cell population might represent a novel therapeutic target in AML.

\section{Background}

Acute myeloid leukemia (AML) is generally regarded as a stem cell disease. It originates from a class of leukemic stem cells that are capable of self-renewal $[1,2]$. AML is a heterogeneous disease, with respect to the causative pathogenic mutations and clinical outcomes [3]. AML can progress aggressively within a short period of time and become lethal. Survival rates for adults with AML are very poor despite extensive chemotherapy and/or targeted therapies, provided along with supportive care [4].

The leukemia stem cells (LSCs) in AML play an important role in the development, relapse and progression of leukemia, and in the development of chemotherapeutic drug resistance in AML [5]. Recent studies have suggested that LSCs are capable of giving rise to identical daughter cells that can differentiate into other cells and maintain AML $[6,7]$. Rhenen et al showed that a high percentage of $\mathrm{CD} 34^{+} \mathrm{CD} 38^{-}$stem cells at diagnosis significantly correlated with a high minimal residual disease frequency and subsequently to relapse in AML patients. These cell populations directly correlated with poor survival $[8,9]$.

Identification and characterization of the LSC population is one of the best ways to develop treatment strategies and to improve treatment outcomes in patients with AML and other malignant diseases [3]. Extensive basic research on the identification and targeting of LSCs is being done globally. Many scientists are interested in this area and have found appropriate biological markers for LSC population in AML, including $\mathrm{CD} 34^{+} \mathrm{CD} 38^{-}$cells $[10,11], \mathrm{CD}^{+} 4^{+}$lin ${ }^{-}$cells [12], CD $34^{+}$Thy $1^{+} \mathrm{CD} 38^{\text {low }}$ cells [13], CD $34^{+} \mathrm{CD} 117^{+}$cells [14], CD $34^{+} \mathrm{CD} 38^{-} \mathrm{CD} 123^{+}$cells [15-17], CD 34 ${ }^{+} \mathrm{CD} 38^{-} \mathrm{CD} 123^{+} \mathrm{CD} 33^{+}$cells [18], CD34 ${ }^{+}$CD38-C-type lectin-like molecule- $1(\mathrm{CLL}-1)^{+}$cells [19], CD34 ${ }^{+}$CD 38-CD $96^{+}$cells [20], CD 34 ${ }^{+}$CD 38 ${ }^{-}$ 
CD45-/low cells [21], CD34/CD123/CD25/CD99 ${ }^{+}$[5], etc. The CD34+CD38- progenitor cells express varying levels of the target receptors, CD33, CD133, and c-kit (CD117) [22]. However, most of the studies have not provided any conclusive data. Therefore, we analyzed the findings from published studies and identified new combinations that could help detect LSCs. We developed this method using the basic CD $34^{+} \mathrm{CD} 38^{-}$ markers to which novel antigens such as CD45 $\mathrm{dim}$ and CD133 were added. In this study, we developed a four-color flow cytometric analysis method, and measured the levels of LSCs in bone marrow cells isolated from $A M L$ patients. Our findings suggest that $C D 45^{\text {dim }} C D 34^{+} C D 38^{-} C D 133^{+}$cells exhibit similar potential as that of LSCs in AML patients.

\section{Methods}

\section{Reagents}

Mouse anti-human CD45-FITC (Clone 2D1, Cat No. 347463), mouse anti-human CD34-PE [Clone 8G12 (also known as HPCA2), Cat No. 348057], mouse anti-human CD38-PE-Cy ${ }^{\text {TM }} 5$ (Clone HIT2, Cat No. 555461), and appropriated isotype control antibodies were purchased from BD Biosciences (San Diego, CA, USA). Mouse anti-human CD133-APC (Clone CD133, Cat No. 130-090-826) was obtained from Miltenyi Biotec (San Diego, CA, USA).

\section{Patient samples}

We analyzed bone marrow samples collected from 87 patients who were newly diagnosed with $A M L(n=$ $40)$, chronic myeloid leukemia ( $C M L, n=6)$, diffuse large B-cell lymphoma ( $D L B C L, n=19)$, multiple myeloma ( $M M, n=10)$, myelodysplastic syndrome (MDS, $n=5)$, Hodgkin lymphoma $(H L, n=4)$, acute lymphocytic leukemia ( $A L L, n=3$ ), or chronic lymphocytic leukemia $(C L L, n=2)$. Control bone marrows were obtained to rule out hematologic disorders but proven to be normal marrows from 27 healthy donors at Ulsan University Hospital, Ulsan South Korea. Baseline clinical characteristics of 40 patients with AML are summarized in Supplementary Table 1. Other patient characteristics (expect AML) are summarized in Supplementary Table 2.

\section{Isolation of bone marrow cells}

The bone marrow cells (BMCs) were isolated by the density gradient method, as previously described [23]. In brief, BMCs were isolated via density gradient centrifugation at $400 \times g$ using Lymphoprep (Axis-Shield, Oslo, Norway; density, $1.077 \mathrm{~g} / \mathrm{mL}$ ). They were washed with phosphate-buffered saline (PBS).

\section{Flow cytometric phenotypic analysis}

The BMCs were collected and washed twice with FACS buffer (PBS containing $0.3 \% \mathrm{BSA}$ and $0.1 \% \mathrm{NaN}_{3}$ ). The total bone marrow cell number used in the experiment was $4 \times 10^{6}$ cells. Cells were incubated with four antibodies against each cell surface antigen, including CD45, CD34, CD38, and CD133 on ice for 30 min. First, live BMCs were collected, and SSClow and CD45 dim cells were gated, as shown in Fig. $1 \mathrm{~A}$ and 
1B. And we always draw gates with the same criteria and select cells in the same section. The criteria are as follows: R1 Gate: live cells; R2 Gate: SSC-H, 100-500 and FL2-H, 10-10²; R3 Gate: FL2-H, 10²-104 , FL3$\mathrm{H}, 10^{0}-10^{1}$. The BMCs were incubated with three combinations of monoclonal antibodies (mAbs) on ice for $30 \mathrm{~min}$; these included isotype control 1 (mouse anti-human CD45-FITC, mouse IgG-PE, mouse IgG-PE CY5, and mouse IgG-APC), isotype control 2 (mouse anti-human CD45-FITC, mouse anti-human CD34-PE, mouse anti-human CD38-PE CY5, and mouse IgG-APC), and sample (mouse anti-human CD45-FITC, mouse anti-human CD34-PE, mouse anti-human CD38-PE CY5, and mouse human CD133-APC), as shown in Fig. 1C and Fig. 1D. Cells were then washed twice with FACS buffer and analyzed using the FACSCalibur flow cytometer and CellQuest Pro software (BD Bioscience) as shown Fig. 1. Finally, the counts of $C D 45^{\text {dim }} C D 34^{+} C D 38^{-} C D 133^{+}$cells, $C D 133$ positive cells among the R1, R2, R3-gated cells were measured, and the results were expressed as percentage change from the basal conditions including the isotype control 2. The 40000 cells were used for flow cytometric acquisition in each sample tube.

\section{ELISA for cytokine measurement}

Cell-free plasma from bone marrow samples of patients with AML was collected and frozen at $-80^{\circ} \mathrm{C}$. Plasma interleukin (IL)-1 $\beta$, IL-6, IL-17, and IL-23 levels were measured using ELISA kits according to the manufacturer's introductions (R\&D Systems).

\section{Statistics}

The data presented here represent the mean \pm standard error of mean (SEM) of at least three independent experiments. All values were evaluated by one-way analysis of variance followed by Turkey range tests implemented in GraphPad Prism 7.0. Differences were considered significant at $P<0.05$. For patients with AML, continuous variables were compared using the Student's $t$-test, whereas categorical variables were analyzed using the Pearson chi-square test or Fisher's exact test. Overall survival (OS) was calculated from the date of HCT to the date of death or last follow-up. Event-free survival (EFS) was defined from the date of HCT to the date of relapse or death from any cause. Survival probabilities were estimated by the Kaplan-Meier method. Univariate and multivariate analyses for OS, EFS, and relapse probability were performed using the log rank test and Cox proportional hazards model, respectively. The following variables were included in univariate analyses: $\mathrm{CD} 45^{\mathrm{dim}} \mathrm{CD} 34^{+} \mathrm{CD} 38^{-} \mathrm{CD} 133^{+}$cell proportion, age, white blood cell (WBC) count, platelet count, bone marrow blast percentage, cytogenetic risk groups, chemotherapeutic regimens, and immunophenotyping including CD7, CD33, CD34, and HLA-DR. Variables with a $P$-value $<0.1$ in the univariate analyses were included in the multivariate analyses. The statistical analyses were performed with SPSS version 21.0 software (IBM Corp., Armonk, NY). For all analyses, the $P$-values were two-sided; a $P$-value of $<0.05$ was considered statistically significant.

\section{Results}

CD45 ${ }^{\text {dim }}$ CD $34^{+}$CD $38^{-}$CD $133^{+}$cells are present in high numbers in the bone marrow of patients with acute myeloid leukemia 
The work flow of the four-color flow cytometry experiments using monoclonal antibodies (mAbs) is shown in Fig. 1. As shown in Fig. 1A and 1B, live BMCs were collected and SSClow/CD45 dim cells were obtained. The BMCs were stained with various combinations of monoclonal antibodies for 30 min such as isotype 1, isotype 2, and sample (Fig. 1C). The CD133 positive cells in the R1, R2, R3-gated cells were measured using flow cytometry, and the results were expressed as percentage changes from the isotype 2 (Fig. 1D). A total of $40 \mathrm{AML}$ patients were examined for the expression of the target antigens, $\mathrm{CD} 45^{\mathrm{dim}} \mathrm{CD} 34^{+} \mathrm{CD} 38^{-} \mathrm{CD} 133^{+}$on the surface of BMCs. These cells were present in high numbers in the bone marrow samples isolated from patients with AML, but not in those of healthy controls (Fig. 2).

These results indicated that $\mathrm{CD} 45^{\mathrm{dim}} \mathrm{CD} 34^{+} \mathrm{CD} 38^{-} \mathrm{CD} 133^{+}$cells in bone marrow are potential AML stem cells.

\section{Elevated IL-1 $\beta$, IL-6, IL-17 and IL-23 cytokine production of plasma in patients with AML}

Recently, Th17 related cytokines such as IL-13, IL-6, IL-17, IL-21, IL-22, and IL-23 play crucial roles in the pathogenesis of many diseases, including inflammatory diseases, autoimmune diseases, and cancers [24]. They have been shown related to Th17 cells. Especially, elevated frequencies of these cytokines in patients with AML have been associated with prognosis [25]. Therefore, we examined the levels of IL-1 $\beta$, IL-6, IL-17 and IL-23 in the bone marrow plasma samples, which were matched to BMCs in AML patients. Plasma samples from the AML patients exhibited higher levels of IL-1 $\beta, I L-6, I L-17$, and IL-23 than those from healthy controls (Fig. 3).

\section{The $\mathrm{CD} 45^{\mathrm{dim}} \mathrm{CD} 34^{+} \mathrm{CD} 38^{-} \mathrm{CD} 133^{+}$cells are prominently detected in the bone marrow of patients with AML and $\mathrm{CML}$}

As shown in Fig. 4, the $\mathrm{CD} 45^{\mathrm{dim}} \mathrm{CD} 34^{+} \mathrm{CD} 38^{-} \mathrm{CD} 133^{+}$cells were examined by four-color flow cytometry in diverse hematological malignancies including AML $(n=40), \operatorname{CML}(n=6), \operatorname{DLBCL}(n=19), \operatorname{MM}(n=10)$, MDS, $(n=5), H L(n=4), \operatorname{ALL}(n=3)$, and CLL $(n=2)$. These cells are significantly detected in the bone marrow of patients with AML and CML, but not in those with DLBCL, MM, MDS, ALL, CLL, and HL. These results indicated that $\mathrm{CD} 45^{\mathrm{dim}} \mathrm{CD} 34^{+} \mathrm{CD} 38^{-} \mathrm{CD} 133^{+}$cells in bone marrow are potential of $\mathrm{AML}$ stem cells. In addition, these cells might be used for the detection of AML stem cells.

\section{Clinical characteristics according to levels of the $\mathrm{CD} 45^{\mathrm{dim}} \mathrm{CD} 34^{+} \mathrm{CD} 38^{-} \mathrm{CD} 133^{+}$cells}

$\mathrm{CD}_{4} 4^{+} \mathrm{AML}$ and $\mathrm{CD} 34^{-} \mathrm{AML}$ among $36 \mathrm{AML}$ patients evaluable for CD34 expression was noted in 30 patients and 6 patients, respectively. The proportion of $\mathrm{CD} 45^{\mathrm{dim}} \mathrm{CD} 34^{+} \mathrm{CD} 38^{-} \mathrm{CD} 133^{+}$cells in CD34- AML were significantly lower than CD34+ ${ }^{+} \mathrm{AML}$ (median, 5.0\% [range, 1-14\%] vs. 13.5\% [range, 1.8-58\%], $P=0.001$, respectively). And CD34 $A M L$ showed tendency to have lower proportion of CD45 ${ }^{\text {dim }}$ CD $34^{+}$CD $38^{-}$CD $133^{+}$cells. FLT3-ITD mutation was rarely found in AML patients with higher counts of $\mathrm{CD} 45^{\mathrm{dim}} \mathrm{CD} 34^{+} \mathrm{CD} 38^{-} \mathrm{CD} 133^{+}$cells $(\geq 10 \%)$ than in patients with fewer $\mathrm{CD} 45^{\mathrm{dim}} \mathrm{CD} 34^{+} \mathrm{CD} 38^{-}$ CD $133^{+}$cells $(<10 \%)(0 \%$ vs. $23.1 \%$, respectively, $P=0.031)$. In addition, higher counts of CD45 ${ }^{\text {dim }}$ CD $34^{+}$CD 38-CD $133^{+}$cells ( $\geq 20 \%$ ) were significantly associated with lower levels of IL- 17 , as 
compared to lower $\mathrm{CD} 45^{\mathrm{dim}} \mathrm{CD} 34^{+} \mathrm{CD} 38^{-} \mathrm{CD} 133^{+}$cells $(<20 \%)(118.0 \mathrm{vs.} 35.0 \mathrm{pg} / \mathrm{ml}$, respectively, $P=$ 0.028). However, there was no significant difference in IL-1 $\beta, L-6$, and IL-23 levels based on the population of $\mathrm{CD} 45^{\mathrm{dim}} \mathrm{CD} 34^{+} \mathrm{CD} 38^{-} \mathrm{CD} 133^{+}$cells.

\section{High proportion of the $\mathrm{CD} 45^{\mathrm{dim}} \mathrm{CD} 34^{+} \mathrm{CD} 38^{-} \mathrm{CD} 133^{+}$cells predicts poor survival in $\mathrm{AML}$ patients}

When we divided AML patients into three groups based on the percentage of $C D 45^{\mathrm{dim}} \mathrm{CD} 34^{+} \mathrm{CD} 38^{-}$ CD133 ${ }^{+}$cells $(<10 \%, 10-40 \%$, and $\geq 40 \%)$, univariate analysis revealed that the 2 -year OS rate was $64.3 \%$, $57.9 \%$, and $0 \%$, respectively $(P<0.001)$ and the 2 -year EFS was $62.3 \%, 37.2 \%$, and $0 \%(P=0.002)$, respectively (Supplementary Table 3 ). Among the three groups $\left(\mathrm{CD} 45^{\mathrm{dim}} \mathrm{CD} 34^{+} \mathrm{CD} 38^{-} \mathrm{CD} 133^{+}\right.$cell proportions $<10 \%, 10-40 \%$, and $\geq 40 \%$ ), no significant differences were observed in baseline clinical factors including age $(P=0.085)$, white blood cell count $(P=0.397)$, platelet count $(P=0.737)$, and chemotherapy intensity $(P=0.158)$. Univariate analyses for OS and EFS in patients with AML revealed that older age (> 60 years) was significantly associated with worse OS than younger age $(32.8 \% \mathrm{vs.} 75 \%$ at 2-year, respectively, $P=0.041$ ) (Supplementary Table 3 ). In addition, patients with higher marrow blast $\%(\geq 60 \%)$ showed significantly lower OS rates than those with lower marrow blast \% (<60\%) $(36.7 \%$ vs. $66.7 \%, P=0.038$ ) (Supplementary Table 3 ). Patients who were treated with intensive chemotherapy showed significantly better OS than those treated with hypomethylating agents $(57.8 \%$ vs. $30.0 \%, P=$ 0.012). When we took into consideration other clinical parameters in univariate and multivariate analyses, higher percentage of $\mathrm{CD} 45^{\mathrm{dim}} \mathrm{CD} 34^{+} \mathrm{CD} 38^{-} \mathrm{CD} 133^{+}$cells ( $\geq 40 \%$ ) was found to be an independent prognostic factor for OS (hazard ratio [HR], 6.052, $P=0.005$ ) and EFS (HR, 9.028, $P=0.002$ ) (Fig. 5. and Table 1). In addition, higher BM blast $(\%) \geq 60 \%(\mathrm{HR}, 2.607<P=0.049)$ and chemotherapy intensity (hypomethylating agents vs. intensive chemotherapy) (HR, 4.058, $P=0.010)$ were significant prognostic factors for OS in multivariate analysis.

\section{Discussion}

The hypothesis that cancer stem cells including LSCs are responsible for the initiation, relapse, and drug resistance of cancers has caused a great deal of excitement in this area of research. The importance of cancer stem cells has been demonstrated in a variety of tumors [6, 25-29]. Especially, LSCs have unlimited capacity of self-renewal and are responsible for the maintenance of leukemia. Because selective eradication of LSCs could lead to considerable therapeutic benefits, there has been an interest in the identification and characterization of the LSC population that controls their development [30, 31]. Therefore, studies related to prognostically relevant and potentially reliable molecular targets are needed.

AML is a hematopoietic disease that is characterized by clonal growth and the accumulation of myelopoietic progenitor cells [31]. It is a devastating disease that is mostly incurable [4]. Moreover, the treatment for AML involves intense cytotoxic treatment as approximately $70 \%$ of the patients with $A M L$ are refractory to initial therapy or undergo relapse [2]. This is at least partially driven by the chemoresistant nature of the LSCs that maintain the disease. Therefore, novel anti-LSC therapies could decrease the number of relapses and improve survival. 
The first LSC compartment that was described had the CD $34^{+}$CD38- immunophenotype $[1,11]$. The CD34 ${ }^{+} \mathrm{CD} 38^{-}$compartment was shown to contain both $\mathrm{CD} 34^{+} \mathrm{CD} 38^{-} \mathrm{LSC}$ and normal hematopoietic

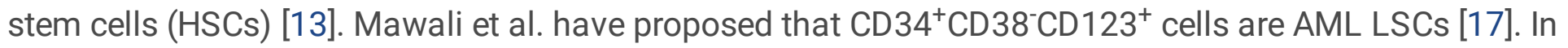
the present study, the $\mathrm{CD} 45^{\mathrm{dim}} \mathrm{CD} 34^{+} \mathrm{CD} 38^{-} \mathrm{CD} 133^{+}$cells were examined by four-color flow cytometry to define a more specific and prognostically significant LSC population (Fig. 1).

In the present study, $C D 34^{+} \mathrm{AML}$ was found in $75 \%$ of patients with $\mathrm{AML}$ and 6 patients had $\mathrm{CD} 34^{-} \mathrm{AML}$. The clinical implications of $\mathrm{CD} 45^{\mathrm{dim}} \mathrm{CD} 34^{+} \mathrm{CD} 38^{-} \mathrm{CD} 133^{+}$cells might be different in CD34 $\mathrm{AML}$. The CD34 AML had lower proportion of $\mathrm{CD} 45^{\operatorname{dim}} \mathrm{CD} 34^{+} \mathrm{CD} 38^{-} \mathrm{CD} 133^{+}$cells. Even though we could not evaluate prognostic impact of $\mathrm{CD} 45^{\mathrm{dim}} \mathrm{CD} 34^{+} \mathrm{CD} 38^{-} \mathrm{CD} 133^{+}$cells in $\mathrm{CD} 34^{-} \mathrm{AML}$ due to small number of patients, some portion of $\mathrm{CD} 45^{\mathrm{dim}} \mathrm{CD} 34^{+} \mathrm{CD} 38^{-} \mathrm{CD} 133^{+}$cells in $\mathrm{CD} 34^{-} \mathrm{AML}$ might contain normal hematopoietic stem cells as well as LSCs.

CD133 has been reported to be a cancer stem cell marker in solid tumors [14, 32-34]. Several studies have shown that CD133 positive cells have the capacity for self-renewal, differentiation, high proliferation, and forming tumors in xenografts $[33,34]$. Although the precise function of CD133 remains unknown, it is associated with aggressive cancers and poor prognosis. CD133 is known to be required for tumor growth and survival $[14,29,32]$. However, in hematological malignancies including AML, the clinical implications of CD133 expression are not well known. Interestingly, $\mathrm{CD} 45^{\mathrm{dim}} \mathrm{CD} 34^{+} \mathrm{CD} 38^{-} \mathrm{CD} 133^{+}$cells are present in more numbers in the bone marrow of patients with $A M L$, but not in healthy controls (Fig. 2). In a further study, only CD133 expression in AML need to be investigated if CD133 marker positivity regardless of CD $34^{+} \mathrm{CD} 38^{-}$might be a significant marker for discriminating LSC and a prognostic biomarker. Moreover, the asynchronism of $\mathrm{CD} 133^{+}$expression should be also evaluated in $\mathrm{CD} 34^{-} \mathrm{AML}$ in the future. In other lymphoid hematologic malignancies such as lymphoma, MM, ALL, and CLL than AML, there could be some differences according to the percentages of both malignant cells and CD $34^{+} \mathrm{CD} 38^{-}$ compartments within bone marrows because of niche competition between two cell populations.

We also found increased production of IL-1 $1 \beta, \mathrm{IL}-6, \mathrm{IL}-17$ and IL-23 in the bone marrow microenvironment of AML patients at the time of diagnosis (Fig. 3). These findings suggest that IL-1 $\beta$, IL-6, IL-17 and IL-23 may be associated with leukemogenesis or pathophysiology of AML. Carey et al. also reported that IL-1 and IL-1 $\beta$ might be associated with AML cell growth [35]. IL-3 plays a key role within the network of cytokines involved in the regulation of hematopoiesis and leukemic blast formation. However, IL-3 has no prognostic significance [20]. As expected, the plasma samples from the AML patients at diagnosis exhibited higher levels of Th17 related cytokines, including IL-1 $\beta$, IL-6, IL-17 and IL-23, than those from healthy controls (Fig. 3). To be honest with you, we expected these cytokines to have some degree of association with LSCs, but it was difficult to find the correlation in the experimental results. More specifically, the prognostic impact of IL-17 in AML is not clear, although higher serum IL-17 levels have been reported to be an adverse prognostic factor of AML in a univariate analysis of IL-17 by Han et al. [25]. In our results, however, IL-17 did not seem to have an adverse impact on prognosis of AML, because IL-17 was inversely correlated with the percentage of CD $45^{\operatorname{dim}} \mathrm{CD} 34^{+} \mathrm{CD} 38^{-} \mathrm{CD} 133^{+} \mathrm{LSC}$ which was 
shown to be a significant negative prognostic marker, considering together clinical factors. There is little data regarding IL-23 levels in AML, although IL-23 levels have been reported to be associated with AML leukemogenesis and disease susceptibility in a previous study [36]. Based on our findings, it may be more advantageous to investigate T helper type 17 (Th17) cell or cell level associations than to monitor cytokines expressed in plasma to understand the association between LSC and Th17.

We applied the gate of $C D 45^{\mathrm{dim}}$ population using the same criteria. Also, our results showed that the individual differences were large for $\mathrm{CD} 45^{\mathrm{dim}}$ population (Supplementary Figure 1 ). In addition, the $\mathrm{CD} 45^{\mathrm{dim}} \mathrm{CD} 34^{+} \mathrm{CD} 38^{-} \mathrm{CD} 133^{+}$cells were prominently detected in the bone marrow of patients with $\mathrm{AML}$ and CML, but not in those with DLBCL, MM, MDS, ALL, CLL, and HL (Fig. 4). Moreover, the prognostic significance of LSCs has been reported in previous studies [1, 17]. Tervinjin et al. showed that higher $\mathrm{CD} 34^{+} \mathrm{CD} 45 \mathrm{LAP}^{+}$cell proportions were related to poor survival [1]. However, our study demonstrated that higher levels of the $\mathrm{CD} 45^{\mathrm{dim}} \mathrm{CD} 34^{+} \mathrm{CD} 38^{-} \mathrm{CD} 133^{+}$cells predict poor OS and EFS in AML (Fig. 5). These results also indicate that the $\mathrm{CD} 45^{\mathrm{dim}} \mathrm{CD} 34^{+} \mathrm{CD} 38^{-} \mathrm{CD} 133^{+}$cell compartment in the bone marrow could help discriminate between LSCs and normal hematopoietic stem cells, and can serve as a strong prognostic marker. Therefore, targeting $\mathrm{CD} 45^{\mathrm{dim}} \mathrm{CD} 34^{+} \mathrm{CD} 38^{-} \mathrm{CD} 133^{+}$cells could serve as a novel therapeutic strategy in AML. Future studies will focus on the elimination of the $\mathrm{CD} 45^{\mathrm{dim}} \mathrm{CD} 34^{+} \mathrm{CD} 38^{-}$ CD $133^{+}$cells in patients with AML. Also, it needs to make sure that $\mathrm{CD} 45^{\mathrm{dim}} \mathrm{CD} 34^{+} \mathrm{CD} 38^{-} \mathrm{CD} 133^{+}$cells actually work as LSCs in the future. And it is necessary to assess whether the CD $45^{\mathrm{dim}} \mathrm{CD} 34^{+} \mathrm{CD} 38^{-}$ $\mathrm{CD}_{133^{+}}$cells have the same characteristics as the stem cells. Therefore, our results indicate that $\mathrm{CD}^{\mathrm{dim}} \mathrm{CD} 34^{+} \mathrm{CD} 38^{-} \mathrm{CD} 133^{+}$cells have the potential of leukemic stem cells in acute myeloid leukemia.

\section{Conclusions}

$\mathrm{CD} 45^{\mathrm{dim}} \mathrm{CD} 34^{+} \mathrm{CD} 38^{-} \mathrm{CD} 133^{+}$cells in $\mathrm{AML}$ might potentially serve as LSCs. Moreover, the high CD $45^{\text {dim }}$ CD $34^{+}$CD $38^{-}$CD $133^{+}$cell counts in AML patients served as a significantly poor risk factor for overall and event free survival. In addition, this cell population might represent a novel therapeutic target in AML.

\section{Abbreviations}

$B M$, bone marrow; $B M C s$, bone marrow cells; $H C$, healthy controls; $A M L$, acute myeloid leukemia; $C M L$, chronic myeloid leukemia; DLBCL, Diffuse large B-cell lymphoma; MM, multiple myeloma; MDS, myelodysplastic syndrome; HL, Hodgkin lymphoma; ALL, acute lymphocytic leukemia; CLL, chronic lymphocytic leukemia.

\section{Declarations}

\section{Acknowledgments}


Not applicable.

\section{Authors' contributions}

SKH, EKN, YC, and JCJ designed the study. SKH, EKN, LJJ, JYS and YKJ performed the experiments. SKH, EKN, YKJ, JC, SK, and YJM analyzed and interpreted the experimental data. SKH, EKN, YKJ, JC, SK, and YJM provided the discussion and suggestions to the experiments. SKH, EKN, YC, and JCJ wrote the manuscript with input from all authors. All authors read and approved the final manuscript.

\section{Funding}

This study was supported by the Basic Science Research Program of the National Research Foundation of Korea (NRF), funded by the Ministry of Education, Science and Technology (NRF-

2017R1A1A3A04069314); and the Biomedical Research Center, funded by the Ulsan University Hospital (UUHBRC-2016-001); and the Korea Health Technology R\&D Project through the Korea Health Industry Development Institute (KHIDI), funded by the Ministry of Health \& Welfare, Republic of Korea (HI17C0904). This work was supported by the Ulsan University Hospital Research Grant (UUH-2019-06).

\section{Availability of data and materials}

All data generated or analyzed during this study are included in this published article and its additional files. Please contact the author Jae-Cheol Jo (jcjo97@hanmail.net) upon reasonable requests.

\section{Ethics approval and consent to participate}

All experiments were performed in accordance with the relevant guidelines and regulations. All patients provided written informed consent before the commencement of the study. The study protocol and patient informed consent form were approved by the Ulsan University Hospital Ethics Committee and Institutional Review Board (UUH-IRB-2016-07-026). The informed written consent was obtained from all included subjects before collecting the bone marrow samples.

\section{Consent for publication}

Not applicable.

\section{Competing interests}

The authors declare that no competing interests exist.

\section{Author details}

${ }^{1}$ Biomedical Research Center, Ulsan University Hospital, University of Ulsan College of Medicine, Ulsan 44033, Republic of Korea. ${ }^{2}$ Department of Hematology and Oncology, Ulsan University Hospital, University of Ulsan College of Medicine, Ulsan 44033, Republic of Korea. 


\section{References}

1. Terwijn M, Zeijlemaker W, Kelder A, Rutten AP, Snel AN, Scholten WJ, Pabst T, Verhoef G, Lowenberg $B$, Zweegman S, et al: Leukemic stem cell frequency: a strong biomarker for clinical outcome in acute myeloid leukemia. PLoS One 2014, 9:e107587.

2. Laverdiere I, Boileau M, Neumann AL, Frison H, Mitchell A, Ng SWK, Wang JCY, Minden MD, Eppert K: Leukemic stem cell signatures identify novel therapeutics targeting acute myeloid leukemia. Blood Cancer J 2018, 8:52.

3. Chan WI, Huntly BJ: Leukemia stem cells in acute myeloid leukemia. Semin Onco/2008, 35:326-335.

4. Roboz GJ: Current treatment of acute myeloid leukemia. Curr Opin Oncol 2012, 24:711-719.

5. Angelini DF, Ottone T, Guerrera G, Lavorgna S, Cittadini M, Buccisano F, De Bardi M, Gargano F, Maurillo L, Divona M, et al: A Leukemia-Associated CD34/CD123/CD25/CD99+ Immunophenotype Identifies FLT3-Mutated Clones in Acute Myeloid Leukemia. Clin Cancer Res 2015, 21:3977-3985.

6. Reya T, Morrison SJ, Clarke MF, Weissman IL: Stem cells, cancer, and cancer stem cells. Nature 2001, 414:105-111.

7. Tan BT, Park CY, Ailles LE, Weissman IL: The cancer stem cell hypothesis: a work in progress. Lab Invest 2006, 86:1203-1207.

8. van Rhenen A, van Dongen GA, Kelder A, Rombouts EJ, Feller N, Moshaver B, Stigter-van Walsum M, Zweegman S, Ossenkoppele GJ, Jan Schuurhuis G: The novel AML stem cell associated antigen CLL-1 aids in discrimination between normal and leukemic stem cells. Blood 2007, 110:2659-2666.

9. van Rhenen A, Moshaver B, Kelder A, Feller N, Nieuwint AW, Zweegman S, Ossenkoppele GJ, Schuurhuis GJ: Aberrant marker expression patterns on the CD34+CD38- stem cell compartment in acute myeloid leukemia allows to distinguish the malignant from the normal stem cell compartment both at diagnosis and in remission. Leukemia 2007, 21:1700-1707.

10. Tolba FM, Foda ME, Kamal HM, Elshabrawy DA: Expression of CD133 in acute leukemia. Med Oncol 2013, 30:527.

11. Bonnet D, Dick JE: Human acute myeloid leukemia is organized as a hierarchy that originates from a primitive hematopoietic cell. Nat Med 1997, 3:730-737.

12. Lapidot T, Sirard C, Vormoor J, Murdoch B, Hoang T, Caceres-Cortes J, Minden M, Paterson B, Caligiuri MA, Dick JE: A cell initiating human acute myeloid leukaemia after transplantation into SCID mice. Nature 1994, 367:645-648.

13. Taussig DC, Miraki-Moud F, Anjos-Afonso F, Pearce DJ, Allen K, Ridler C, Lillington D, Oakervee H, Cavenagh J, Agrawal SG, et al: Anti-CD38 antibody-mediated clearance of human repopulating cells masks the heterogeneity of leukemia-initiating cells. Blood 2008, 112:568-575.

14. Park EK, Lee JC, Park JW, Bang SY, Yi SA, Kim BK, Park JH, Kwon SH, You JS, Nam SW, et al: Transcriptional repression of cancer stem cell marker CD133 by tumor suppressor p53. Cell Death Dis 2015, 6:e1964. 
15. Wang W, Wang HY, Zhao HX, Cui ZG, Li GL: [Expression of CD133 in bone marrow cells of patients with leukemia and myelodysplastic syndrome]. Zhongguo Shi Yan Xue Ye Xue Za Zhi 2007, 15:470473.

16. Reikvam H, Brenner AK, Hagen KM, Liseth K, Skrede S, Hatfield KJ, Bruserud O: The cytokinemediated crosstalk between primary human acute myeloid cells and mesenchymal stem cells alters the local cytokine network and the global gene expression profile of the mesenchymal cells. Stem Cell Res 2015, 15:530-541.

17. Al-Mawali A, Gillis D, Lewis I: Immunoprofiling of leukemic stem cells CD34+/CD38-/CD123+ delineate FLT3/ITD-positive clones. J Hematol Oncol 2016, 9:61.

18. Hauswirth AW, Florian S, Printz D, Sotlar K, Krauth MT, Fritsch G, Schernthaner GH, Wacheck V, Selzer E, Sperr WR, Valent P: Expression of the target receptor CD33 in CD34+/CD38-/CD123+ AML stem cells. Eur J Clin Invest 2007, 37:73-82.

19. Guenova M, Balatzenko G: CD133-2 (AC141) expression analysis in acute leukemia immunophenotyping in correlation to CD34 and P-glycoprotein. Hematology 2008, 13:137-141.

20. Binder S, Luciano M, Horejs-Hoeck J: The cytokine network in acute myeloid leukemia (AML): A focus on pro- and anti-inflammatory mediators. Cytokine Growth Factor Rev 2018, 43:8-15.

21. Toren A, Bielorai B, Jacob-Hirsch J, Fisher T, Kreiser D, Moran O, Zeligson S, Givol D, Yitzhaky A, Itskovitz-Eldor J, et al: CD133-positive hematopoietic stem cell "stemness" genes contain many genes mutated or abnormally expressed in leukemia. Stem Cells 2005, 23:1142-1153.

22. Mak AB, Nixon AM, Moffat J: The mixed lineage leukemia (MLL) fusion-associated gene AF4 promotes CD133 transcription. Cancer Res 2012, 72:1929-1934.

23. Heo SK, Noh EK, Yoon DJ, Jo JC, Park JH, Kim H: Dasatinib accelerates valproic acid-induced acute myeloid leukemia cell death by regulation of differentiation capacity. PLoS One 2014, 9:e98859.

24. Li P, Ji M, Park J, Bunting KD, Ji C, Tse W: Th17 related cytokines in acute myeloid leukemia. Front Biosci (Landmark Ed) 2012, 17:2284-2294.

25. Han Y, Ye A, Bi L, Wu J, Yu K, Zhang S: Th17 cells and interleukin-17 increase with poor prognosis in patients with acute myeloid leukemia. Cancer Sci 2014, 105:933-942.

26. Morrison SJ, Uchida N, Weissman IL: The biology of hematopoietic stem cells. Annu Rev Cell Dev Biol 1995, 11:35-71.

27. Weissman IL: Stem cells: units of development, units of regeneration, and units in evolution. Cell 2000, 100:157-168.

28. Al-Hajj M, Wicha MS, Benito-Hernandez A, Morrison SJ, Clarke MF: Prospective identification of tumorigenic breast cancer cells. Proc Natl Acad Sci U S A 2003, 100:3983-3988.

29. Lu L, Wu M, Sun L, Li W, Fu W, Zhang X, Liu T: Clinicopathological and prognostic significance of cancer stem cell markers CD44 and CD133 in patients with gastric cancer: A comprehensive metaanalysis with 4729 patients involved. Medicine (Baltimore) 2016, 95:e5163. 
30. Wang Y, Krivtsov AV, Sinha AU, North TE, Goessling W, Feng Z, Zon LI, Armstrong SA: The Wnt/betacatenin pathway is required for the development of leukemia stem cells in AML. Science 2010, 327:1650-1653.

31. Sperr WR, Hauswirth AW, Florian S, Ohler L, Geissler K, Valent P: Human leukaemic stem cells: a novel target of therapy. Eur J Clin Invest 2004, 34 Suppl 2:31-40.

32. Joseph C, Arshad M, Kurozomi S, Althobiti M, Miligy IM, Al-Izzi S, Toss MS, Goh FQ, Johnston SJ, Martin SG, et al: Overexpression of the cancer stem cell marker CD133 confers a poor prognosis in invasive breast cancer. Breast Cancer Res Treat 2018.

33. Singh SK, Hawkins C, Clarke ID, Squire JA, Bayani J, Hide T, Henkelman RM, Cusimano MD, Dirks PB: Identification of human brain tumour initiating cells. Nature 2004, 432:396-401.

34. Wu Y, Wu PY: CD133 as a marker for cancer stem cells: progresses and concerns. Stem Cells Dev 2009, 18:1127-1134.

35. Carey A, Edwards DKt, Eide CA, Newell L, Traer E, Medeiros BC, Pollyea DA, Deininger MW, Collins RH, Tyner JW, et al: Identification of Interleukin-1 by Functional Screening as a Key Mediator of Cellular Expansion and Disease Progression in Acute Myeloid Leukemia. Cell Rep 2017, 18:3204-3218.

36. Qian X, Cao S, Yang G, Pan Y, Yin C, Chen X, Zhu Y, Zhuang Y, Shen Y, Hu Z: Potentially functional polymorphism in IL-23 receptor and risk of acute myeloid leukemia in a Chinese population. PLOS One 2013, 8:e55473.

\section{Tables}

Table 1. Multivariate analysis for patients with acute myeloid leukemia.

\begin{tabular}{|c|c|c|c|c|}
\hline & HR for OS & $P$-value & HR for EFS & $P$-value \\
\hline \multicolumn{5}{|l|}{ 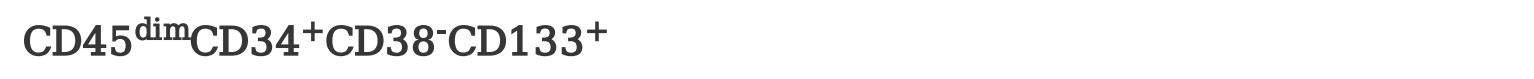 } \\
\hline$<10 \%(\mathrm{n}=14)$ & 1 & & 1 & \\
\hline $10-<40 \%(\mathrm{n}=19)$ & 1.859 & 0.276 & 2.731 & 0.089 \\
\hline$\geq 40 \%(\mathrm{n}=7)$ & 6.052 & 0.005 & 9.028 & 0.002 \\
\hline \multicolumn{5}{|l|}{ BM blast (\%) } \\
\hline$<60 \%(\mathrm{n}=16)$ & 1 & & - & - \\
\hline$\geq 60 \%(\mathrm{n}=24)$ & 2.607 & 0.049 & & \\
\hline \multicolumn{5}{|l|}{ Chemotherapy } \\
\hline Intensive chemotherapy $(n=30)$ & 1 & & 1 & \\
\hline Hypomethylating agent $(n=10)$ & 4.058 & 0.010 & 4.829 & 0.010 \\
\hline
\end{tabular}

HR, hazard ratio; OS, overall survival; EFS, event free survival. 


\section{Additional File Legends}

Additional file 1: Supplementary Table 1. Baseline characteristics of AML patients.

Additional file 2: Supplementary Table 2. Patient characteristics.

Additional file 3: Supplementary Table 3. Univariate analysis for AML patients.

Additional file 4: Supplementary Figure 1. The expression of CD45 dim population on bone marrow cells in the study.

Figures 
Fig. 1. Heo et al.

\section{A Live cells-gated}

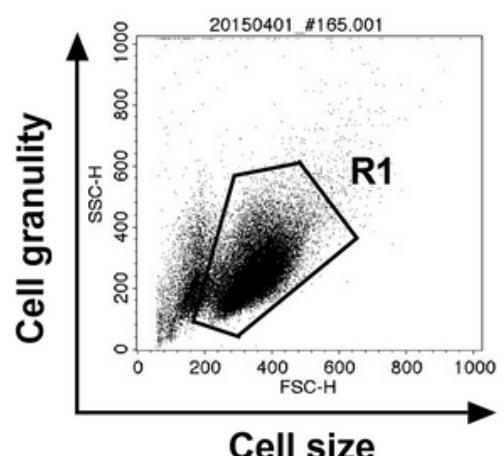

B R1-gated

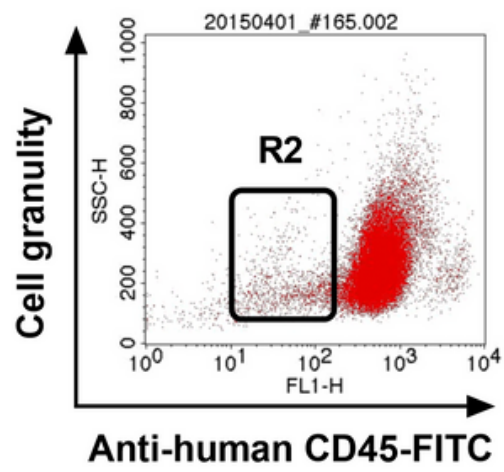

\section{R1, R2-gated}

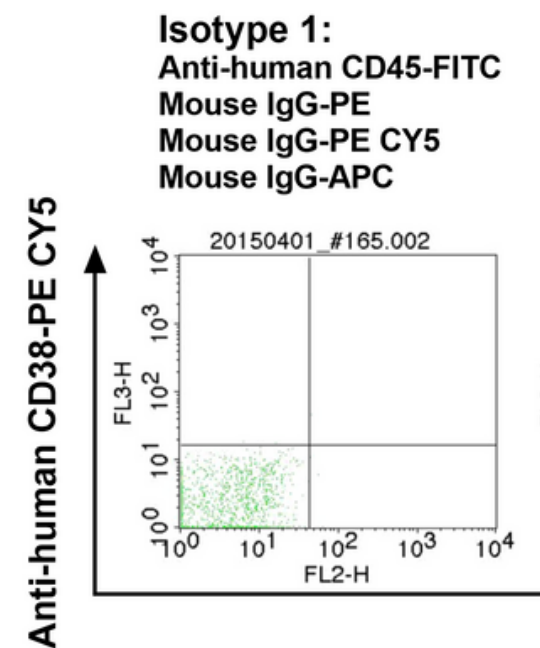

Isotype 2:

Anti-human CD45-FITC

Anti-human CD34-PE

Anti-human CD38-PE CY5

Mouse IgG-APC

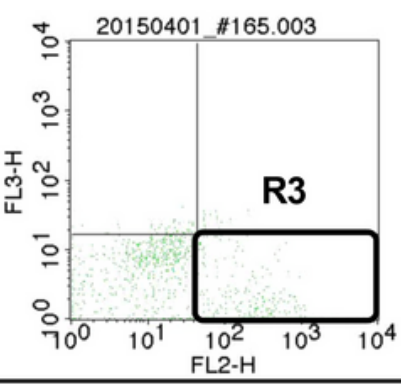

Sample:

Anti-human CD45-FITC

Anti-human CD34-PE

Anti-human CD38-PE CY5

Anti-human CD133-APC

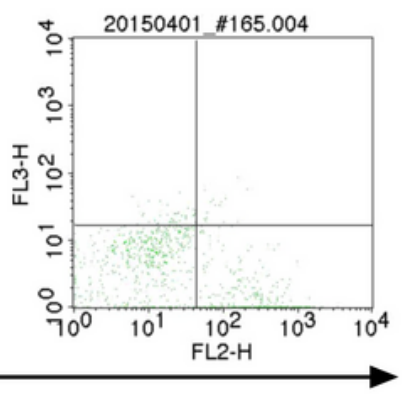

Anti-human CD34-PE

Overlay of

D R1, R2, R3-gated isotype 2 and sample

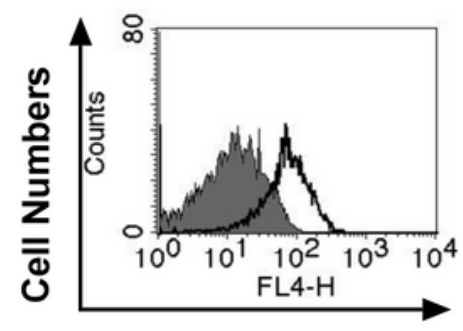

Anti-human CD133-APC

\section{Figure 1}

The process of four-color staining flow cytometry using monoclonal antibodies. The BMCs were collected and washed twice with FACS buffer. Cells were incubated with four antibodies against cell surface antigens, including CD45, CD34, CD38, and CD133 on ice for 30 min. (A, B) The live BMCs were collected, and SSClow and CD45dim cells were gated. (C, D) The BMCs were incubated with three types of combinations of monoclonal antibodies (mAbs) on ice for 30 min such as isotype control 1 (mouse anti- 
human CD45-FITC, mouse IgG-PE, mouse IgG-PE CY5 and mouse IgG-APC), isotype control 2 (mouse antihuman CD45-FITC, mouse anti-human CD34-PE, mouse anti-human CD38-PE CY5, and mouse IgG-APC), and sample (mouse anti-human CD45-FITC, mouse anti-human CD34-PE, mouse anti-human CD38-PE $\mathrm{CY} 5$, and mouse human CD133-APC). Cells were then washed twice with FACS buffer and analyzed using the FACSCalibur flow cytometer and CellQuest Pro software (BD Bioscience). Finally, the levels of CD45dimCD34+CD38-CD133+ cells, CD133 positive cells among the R1, R2, R3-gated cells were measured and the results were expressed as percentage change from the baseline conditions including isotype control 2. The filled histogram represents the isotype control 2, and the empty histogram represents CD45dimCD34+CD38-CD133+ cells. 


\section{Fig. 2. Heo et al}

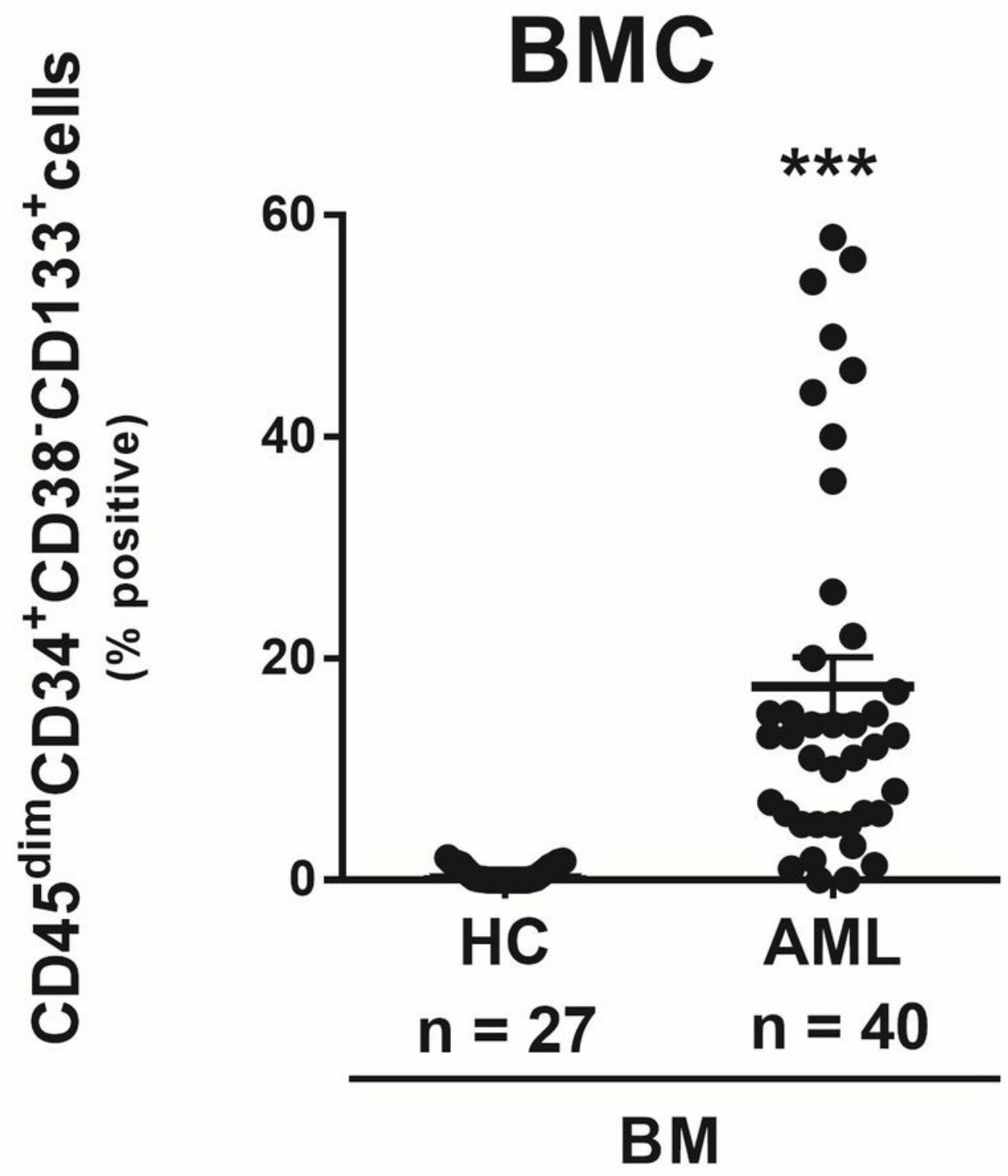

Figure 2

The CD45dimCD34+CD38-CD133+ cells are highly expressed in bone marrow of patients with AML, not healthy controls. Bone marrow cells from healthy controls and AML patients were examined for expression of the target antigens, CD45dimCD34+CD38-CD133+ cells. Data represent mean \pm SEM representing three independent experiments from different AML patients. Significantly different from the control (*); ***, $P<0.001$. HC, healthy controls; AML, Acute myeloid leukemia patients. 
Fig. 3. Heo et al
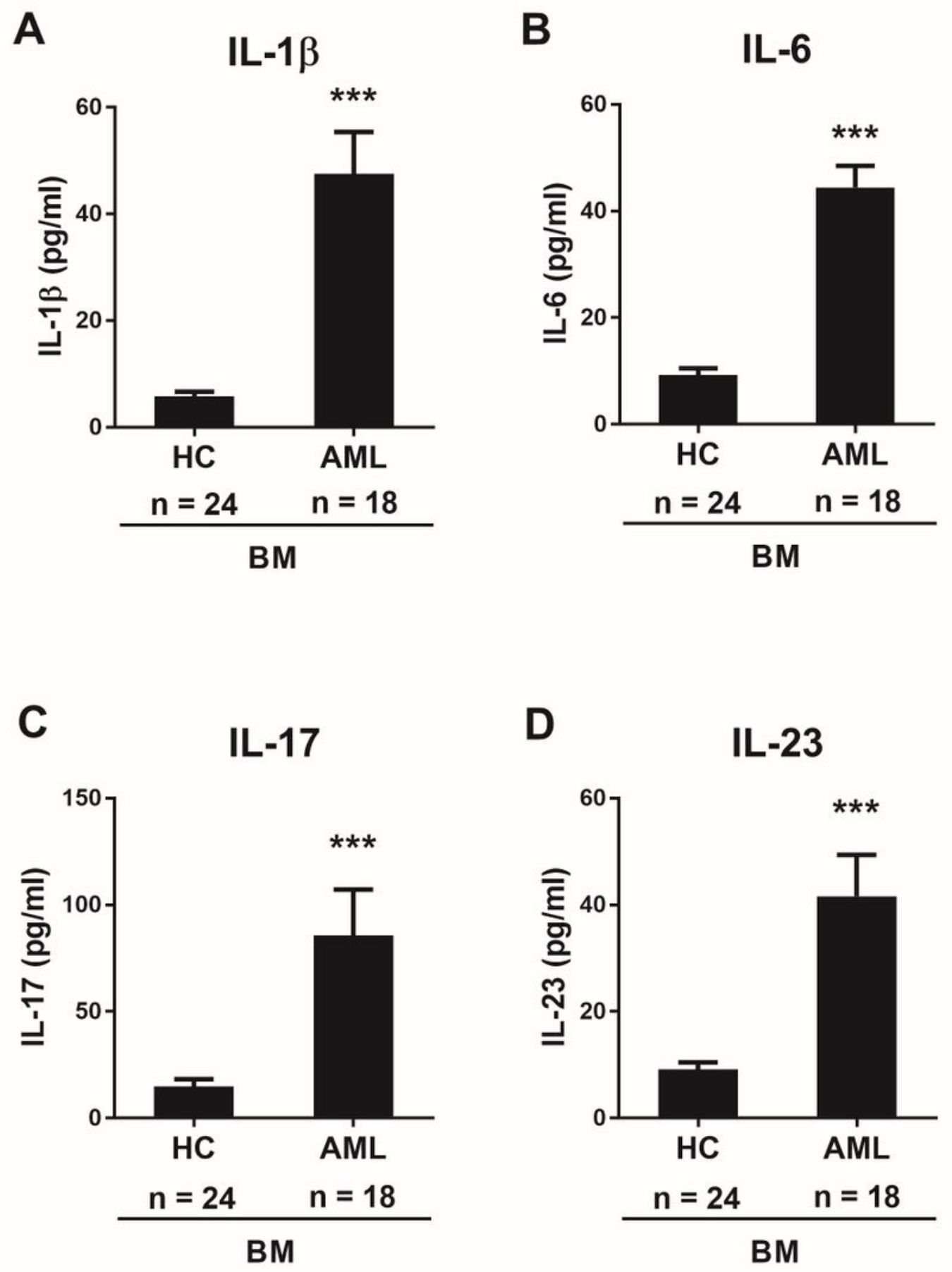

Figure 3

Measure the production of cytokines in plasma from healthy controls and AML patients. Cell-free plasmas from bone marrow samples from patients with $A M L$ were collected and frozen at $-80^{\circ} \mathrm{C}$. Plasma levels of interleukin (IL)-1 $\beta$, IL-6, IL-17 and IL-23 were measured using ELISA kits according to manufacturer's introductions (R\&D Systems). Data represent mean \pm SEM representing three independent 
experiments from different AML patients. Significantly different from the control (*); ${ }^{\star \star \star}, P<0.001$. HC, healthy controls; AML, Acute myeloid leukemia patients; BM, Bone marrow.

\section{Fig. 4. Heo et al}

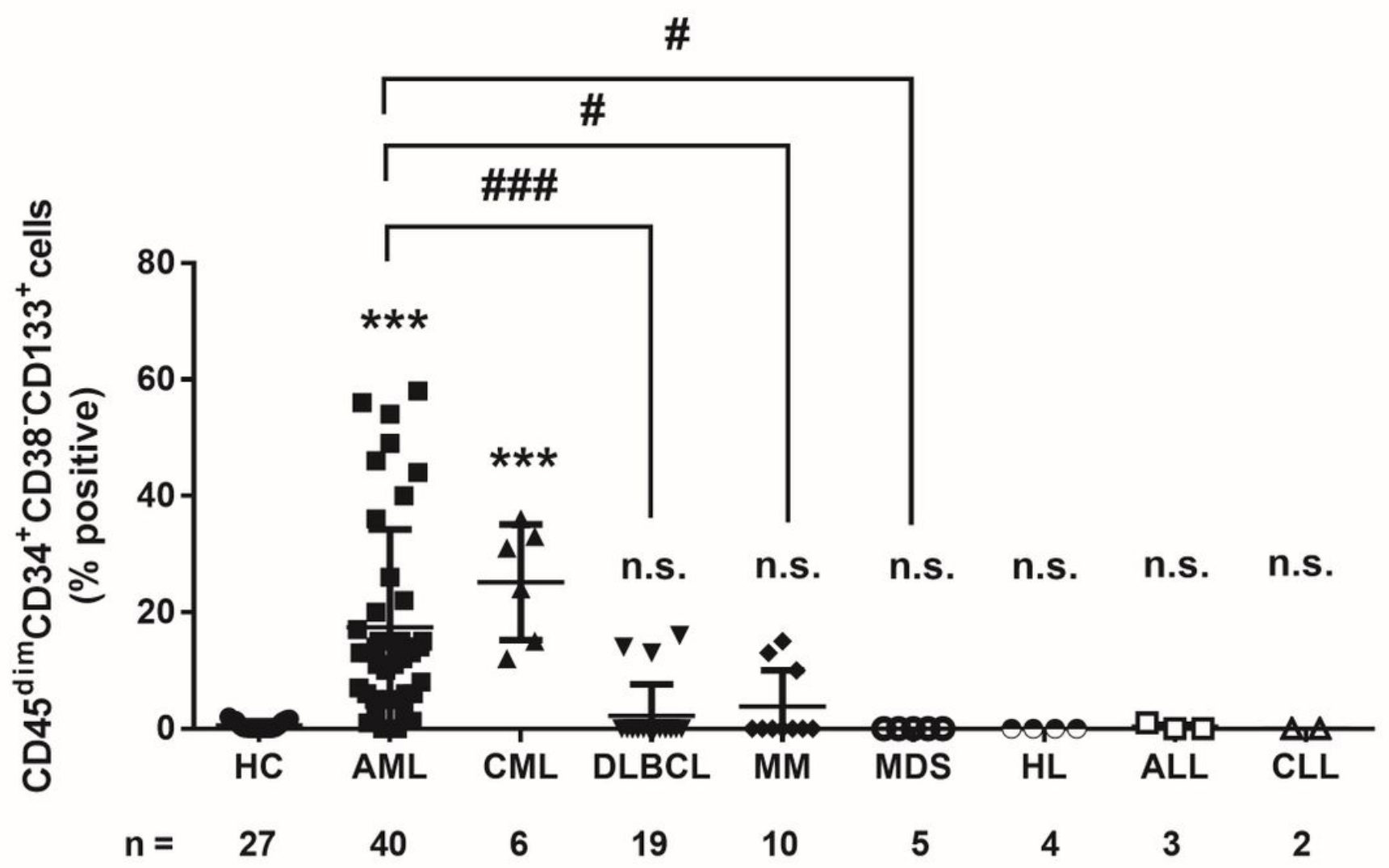

Figure 4

. The CD45dimCD34+CD38-CD133+ cells are prominently detected in BMCs of patients with AML and CML. As shown in Fig. 1, the CD45dimCD34+CD38-CD133+ cells were examined by four-color flow cytometry experiments in diverse hematology malignancy including AML $(n=40), C M L(n=6), D L B C L(n$ $=19), M M(n=10), M D S,(n=5), H L(n=4), \operatorname{ALL}(n=3)$ and CLL $(n=2)$. Data represent mean \pm SEM representing three independent experiments from different $A M L$ patients. Significantly different from the

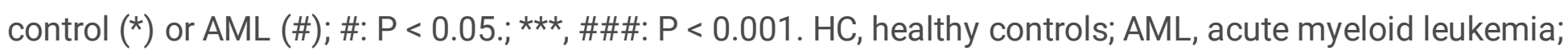
$\mathrm{CML}$, chronic myeloid leukemia; DLBCL, Diffuse large B-cell lymphoma; MM, multiple myeloma; MDS, myelodysplastic syndrome; HL, Hodgkin lymphoma; ALL, acute lymphocytic leukemia; CLL, chronic lymphocytic leukemia. 
Fig. 5. Heo et al

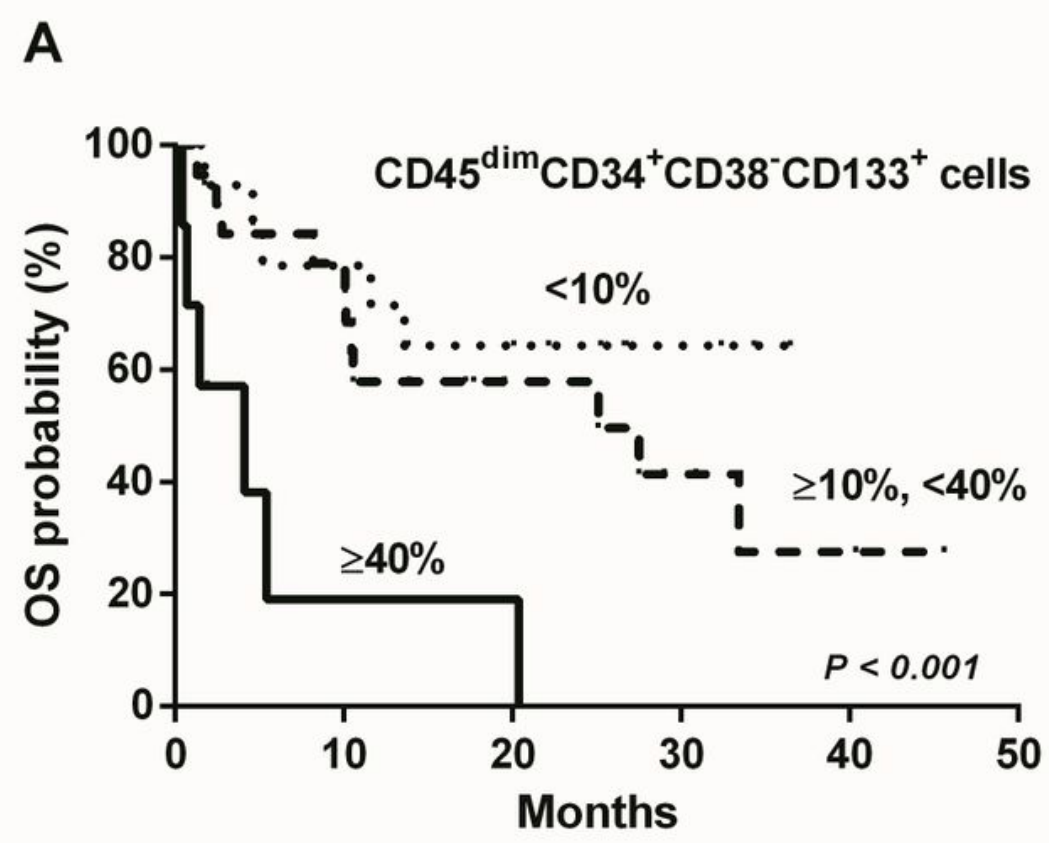

B

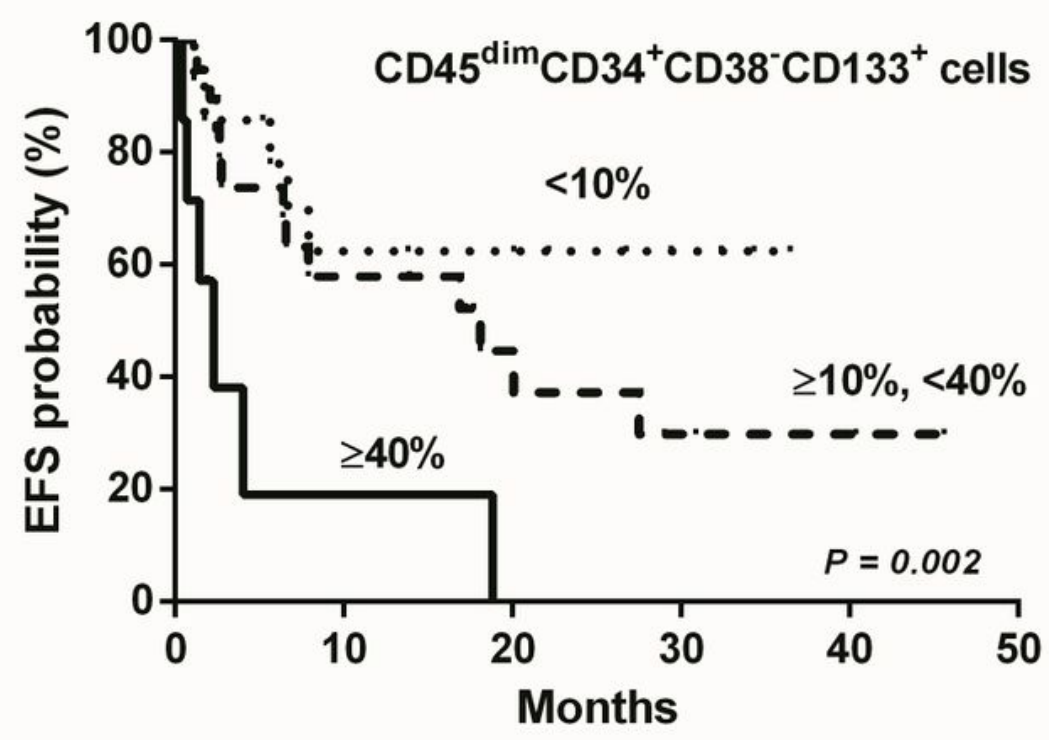

Figure 5

High proportion of the CD45dimCD34+CD38-CD133+ cells predicts poor survival in AML patients. (A) Higher CD45dimCD34+CD38-CD133+ cell proportion was significantly associated with worse OS $(\mathrm{P}<$ 0.001). (B) Poorer EFS was significantly associated with higher CD45dimCD34+CD38-CD133+ cell proportion $(P=0.002)$. 


\section{Supplementary Files}

This is a list of supplementary files associated with this preprint. Click to download.

- 20200224LSCSupplementaryTablesRevisionversion.docx 